\title{
DEPENDÊNCIA CULTURAL E MEMÓRIA DO ENSINO DE LÍNGUAS E LITERATURAS ESTRANGEIRAS NO BRASIL
}

\section{CULTURAL DEPENDENCE AND MEMORY OF THE TEACHING OF FOREIGN LANGUAGES AND LITERATURES IN BRAZIL}

\author{
Antonio Andrade ${ }^{1}$
}

\begin{abstract}
RESUMO: Neste artigo discutimos a problemática da dependência cultural na memória discursiva que atravessa a relação entre o ensino de línguas e de literaturas estrangeiras no Brasil, com ênfase sobre o lugar singular ocupado pelo espanhol e as literaturas hispânicas neste contexto. Nossa investigação focaliza arquivos históricos do Colégio Pedro II, considerado escola-modelo da educação nacional desde o século XIX até meados do século XX.
\end{abstract}

PALAVRAS-CHAVE: dependência cultural; línguas e literaturas estrangeiras; espanhol e literaturas hispânicas; memória discursiva; Colégio Pedro II.

\begin{abstract}
In this article, we discuss the issue of cultural dependence in the discursive memory of the relation between the teaching of foreign languages and literatures in Brazil, with emphasis on the singular place occupied by Spanish and Hispanic literatures in this context. Our research focuses on the historical archives of Pedro II School, considered a model for national education from $19^{\text {th }}$ century to the mid-20 $0^{\text {th }}$ century.
\end{abstract}

KEYWORDS: cultural dependence; foreign languages and literatures; Spanish and Hispanic literatures; discursive memory; Pedro II School.

Neste artigo, analisamos o histórico da presença das literaturas estrangeiras, com ênfase sobre as literaturas hispânicas, nos currículos que se sucederam ao longo do tempo no Colégio Pedro II (RJ) com o intuito de refletir sobre questões relativas à memória discursiva que no contexto brasileiro abriga a vinculação entre literatura e ensino de línguas estrangeiras, de um modo geral, bem como a relação entre literatura e ensino de língua espanhola, de maneira específica. Ou seja, embora partamos do foco sobre um percurso institucional particular, o próprio fato de historicamente o Colégio Pedro II ter servido como modelo para a educação nacional nos faz trazer à baila hipóteses analíticas que supõem muitas das práticas discursivas em torno dos modos de aproveitamento da literatura no ensino de idiomas estrangeiros para além das fronteiras desta instituição. É importante destacar desde o início que esta memória passou por ressignificações decorrentes de inúmeros fatores e agenciamentos históricos, ainda que sejam perceptíveis determinados eixos ou linhas de força que permanecem em tensão e acabam por emergir de diferentes formas nas abordagens do literário no campo disciplinar língua estrangeira moderna no Brasil.

Consultando os atos legislativos que serviram historicamente de diretrizes para o Pedro II, constatamos algumas questões relevantes para nossa reflexão. Em primeiro lugar, observamos uma forte ligação entre o ensino de línguas estrangeiras (quais sejam: alemão, francês, inglês e italiano) e de suas respectivas literaturas. Notem-se a seguir, a título de exemplificação, alguns fragmentos de decretos destinados a dar regulamentação ao Colégio

\footnotetext{
${ }^{1}$ Universidade Federal do Rio de Janeiro - UFRJ, Rio de Janeiro, Rio de Janeiro, Brasil; https://orcid.org/00000003-1126-9630; antonioandrade.ufrj@gmail.com
} 
Pedro II, em particular, ou a todo o sistema educacional brasileiro, na segunda metade do século XIX e início do século XX. O Decreto N. 4468, de $1^{\circ}$ de fevereiro de 1870 , indica, para o $7^{\circ}$ ano, por exemplo, o aperfeiçoamento nas línguas francesa e inglesa, com "prelecções elementares sobre a indole, formação e progresso de cada uma das referidas linguas, alternadas com a leitura, traducção e apreciação litteraria de autores clássicos". ${ }^{2}$ O Decreto N. 6130, de $1^{\circ}$ de março de 1876, para a cadeira de inglês, no $5^{\circ}$ ano, fala nos seguintes conteúdos disciplinares: "Grammatica, themas, versão de prosadores e poetas portuguezes e inglezes, gradualmente mais difficeis; conversação". De forma similar, o Decreto N. 6884, de 20 de abril de 1878, aponta que o ensino de alemão, no $4^{\circ}$ ano, deve contemplar "Grammatica, themas, leitura, versão de prosadores e poetas faceis portuguezes e alemães". O Decreto N. 8051, de 24 de março de 1881, diz que a disciplina de italiano, no $7^{\circ}$ ano, deve abordar "Grammatica: exercicios de composição e derivação de palavras; themas, leitura, recitação, analyse e versão de prosadores e poetas italianos e portuguezes; conversação. Noticia succinta da origem, desenvolvimento e indole da lingua italiana". O Decreto N. 1075, de 22 de novembro de 1890, indica para a cadeira de francês, no $3^{\circ}$ ano, "grammatica complementar, traducção de autores mais difficeis; exercicios de versão e conversação". No Art. 19, do Decreto N. 2857, de 30 de março de 1898, estipulase que nas "linguas vivas os programmas terão em vista que o alumno se torne apto no manejo das obras principaes da litteratura franceza e ingleza dos seculos XVII, XVIII e actual, e da allemã de Goethe em deante, e que adquira alguma pratica no uso da lingua corrente, quer oral quer escripta". Já no Art. $3^{\circ}$, do Decreto N. 8.660, de 5 de abril de 1911, ordena-se que sejam ministradas as disciplinas de "Francez, estudo pratico e litterario" e de "Inglez ou allemão (á escolha do estudante), estudo pratico e litterario".

É importante ressaltar, contudo, que determinadas tensões em torno das concepções de ensino de línguas, as quais afetam evidentemente a relação entre línguas e literaturas estrangeiras, começam a aparecer na legislação educacional já nas primeiras décadas do século XX. Neste sentido, no Art. 170, das "Disposições especiaes" relativas ao "Collegio Pedro II", que consta do Decreto N. 11.530, de 18 de março de 1915, afirma-se, num movimento oposto ao que se pôde observar nos excertos citados anteriormente, que "O estudo de linguas vivas estrangeiras será exclusivamente pratico, de modo que o estudante se torne capaz de fallar e ler, em Francez, Inglez ou Allemão, sem vacillar nem recorrer frequentemente ao dicionário".

Apesar disso, no período da Primeira República, na passagem do século XIX para o XX, é possível notarmos, no âmbito das políticas linguísticas e literárias vinculadas à consolidação da identidade nacional, a persistência de uma concepção hegemônica a respeito da necessidade de vínculo entre o ensino de línguas e de literaturas estrangeiras, pautada nos efeitos imaginários engendrados pela noção de dependência cultural do Brasil em relação às culturas europeias, a qual possui ampla ancoragem em nossa memória discursiva. Tal relação de dependência, não à toa, reverbera em muitos enunciados produzidos no domínio da historiografia literária brasileira, como se pode perceber no clássico prefácio da Formação da literatura brasileira (momentos decisivos), de Antonio Candido:

A [literatura] brasileira é recente, gerou no seio da portuguesa e dependeu da influência de mais duas ou três para se constituir. [...]

Há literaturas de que um homem não precisa sair para receber cultura e enriquecer a sensibilidade; outras, que só podem ocupar uma parte de sua vida de leitor, sob pena de lhe restringirem irremediavelmente o horizonte. Assim, podemos imaginar um francês, um italiano, um inglês, um alemão, mesmo um russo e um espanhol, que só conheçam os autores da sua terra e, não obstante, encontrem neles o suficiente para elaborar a visão das coisas, experimentando as mais altas emoções literárias.

\footnotetext{
${ }^{2}$ Serão mantidas, neste capítulo, as grafias originais das épocas em que os documentos citados foram redigidos, reproduzindo-os fidedignamente da maneira como foram publicados.
} 
Se isto já é impensável no caso de um português, o que se dirá de um brasileiro? A nossa literatura é galho secundário da portuguesa, por sua vez arbusto de segunda ordem no jardim das Musas... (Candido, 2000, p. 9)

Nesse prefácio, escrito em 1957, podemos observar que Candido, ao topicalizar a ideia de influência como norteadora de sua reflexão a respeito da história de constituição do sistema literário brasileiro, produz uma separação entre literaturas "autônomas" e literaturas "dependentes". A partir desta divisão, o crítico constrói enunciativamente outras formas de hierarquização, pois ainda que considere as literaturas francesa, italiana, inglesa e alemã como autossuficientes, sem lugar a dúvidas, ao introduzir a menção às literaturas russa e espanhola com o modalizador "mesmo", traz à tona discursivamente polêmicas de sua época a respeito do reconhecimento de tais campos literários na mesma categoria das ditas "grandes" literaturas europeias. Ato seguinte, estabelecendo uma escala de correlações, o autor nega à literatura portuguesa equivalente status de autonomia e, por sua vez, ao asseverar que a literatura produzida no Brasil (ex-colônia de Portugal) seria um "galho secundário da portuguesa", refuta a possibilidade de a enxergarmos analiticamente fora do espectro de sua "dependência" em relação à antiga metrópole colonial e ao cânone literário europeu, de maneira geral.

Com base ainda na legislação que regeu as estruturas curriculares do Colégio Pedro II, podemos perceber também, na esfera pedagógica, uma relação de dependência da literatura brasileira em relação às literaturas estrangeiras (quase sempre, da Europa), muitas vezes incluídas, sob uma clave universalizante, no rol da chamada literatura geral, o que constitui no nível enunciativo uma dicotomização entre os significantes "geral" e "nacional". Citemos adiante, a modo de exemplo, excertos de textos legislativos que mencionam formas de denominação e conteúdos estabelecidos para as cadeiras de ensino de literatura na referida instituição. No Decreto N. 4468, de $1^{\circ}$ de fevereiro de 1870 , menciona-se, por exemplo, o curso de "Rhetorica e poetica, historia da litteratura em geral, e em particular da portuguesa e nacional". No Decreto N. 6130, de $1^{\circ}$ de março de 1876, na disciplina nomeada como "Litteratura nacional", exige-se, de acordo com uma visão genealógica do literário, o ensino de "Noções sobre as litteraturas estrangeiras que mais ou menos influiram para a formação ou aperfeiçoamento da portugueza; estudo detido das differentes phases desta e da luso-brazileira; juizos criticos e parallelos dos principaes prosadores e poetas, por escripto". Poucos anos depois, no Decreto N. 6884, de 20 de abril de 1878, as literaturas estrangeiras passam a integrar o mesmo lócus disciplinar em que se ministra a língua oficial do Império, na cadeira designada como "Portuguez e litteratura geral", na qual se insere o ensino de "Litteraturas estrangeiras e estudo especial das que influiram para a formação e aperfeiçoamento da portuguesa". De maneira semelhante, no Decreto N. 8051, de 24 de março de 1881, essa cadeira, que ganha o nome de "Portuguez e Historia Litteraria", deve também contemplar os "Principaes periodos litterarios das linguas mortas e vivas, mórmente das que concorrem para a formação e desenvolvimento da portuguesa". Já no início do período republicano, no Decreto N. 2857, de 30 de março de 1898, a disciplina literária passa a ser denominada como "Litteratura geral e nacional".

Como pudemos ver, tanto as cadeiras literárias quanto as de idiomas eram corresponsáveis pelo ensino de aspectos relativos às literaturas estrangeiras. Subentende-se, nas fontes pesquisadas, que a particularidade das disciplinas de línguas seria criar condições para que os estudantes tivessem acesso aos textos escritos em outro idioma, propiciando assim os processos de leitura, compreensão, tradução e apreciação estética dos mesmos, ao passo que a função prioritária dos cursos de literatura seria a de visibilizar, numa perspectiva histórica, noções e/ou estilos literários de origens europeias que influíram "para a formação ou aperfeiçoamento" da literatura portuguesa, vinculada metonimicamente ao desenvolvimento da 
literatura brasileira (em determinado momento, identificada inclusive como "luso-brazileira") num processo de naturalização discursiva da ideia de filiação colonial.

$* * * * *$

Cabe-nos, agora, assinalar uma diferença significativa da área de espanhol em comparação às de alemão, francês, inglês e italiano no histórico do Colégio Pedro II. Enquanto estas línguas estrangeiras modernas já vinham sendo lecionadas, desde o período imperial, em concomitância ao ensino de conteúdos relativos às literaturas alemã, francesa, inglesa e italiana, a cadeira de língua espanhola só foi criada, efetivamente, no Colégio Pedro II, em 1919. ${ }^{3}$ No entanto, noções de literatura espanhola e hispano-americana já integravam os currículos de literatura geral ou de história literária da instituição desde o século XIX. Ou seja, isto significa dizer que tópicos relacionados aos estudos de literaturas hispânicas emergiram na formação curricular da escola brasileira antes dos que se vinculam aos estudos de língua espanhola. Tal diferença parece corroborar, em certa medida, a hipótese presente no trabalho de doutorado de Celada (2002) de que o espanhol no imaginário brasileiro é visto como uma "língua singularmente estrangeira", a que devido à ilusão de evidência dos sentidos não se atribuiu historicamente "um saber pelo qual valesse a pena o esforço de submeter-se a seu estudo" (ibidem, p. 33), naturalizando assim, no nível do interdiscurso, a correlação entre as ideias de proximidade linguística e facilidade. Contudo, seria possível também, por outro lado, indagarmos: que lugar de saber então representavam aí as literaturas de língua espanhola? Que assimetrias linguístico-culturais estariam implicadas nesta diferença em relação às outras línguas/literaturas ensinadas naquele momento histórico (e talvez até o tempo presente)?

Tomando de empréstimo dados gerados pela investigação de mestrado de Guimarães (2016, p. 71-72), chamamos a atenção para o fato de que, de 1870 a 1875, as literaturas espanhola e hispano-americana aparecem no Pedro II como "Parte do programa de ensino da matéria [...] História da literatura em geral, e em particular da portuguesa e nacional"; de 1876 a 1880, noções de literatura espanhola constam como "Parte do programa de ensino da matéria [...] Literatura Nacional"; de 1881 a 1890, os principais períodos literários das literaturas espanhola e hispano-americana constituem "Parte do programa de ensino da cadeira de Português e História Literária"; e de 1898 a 1912, as literaturas espanhola e hispano-americana são incluídas como "Parte do conteúdo da cadeira de Literatura Geral e Nacional". ${ }^{4}$ Note-se, deste modo, que existia, de fato, um espaço curricular para os saberes constituídos em torno dos estudos literários hispânicos, entretanto este parece ser um espaço secundário, que não servia ao campo literário brasileiro enquanto paradigma a ser seguido, mas pelo contrário, um componente a ser recalcado de sua rede de conexões interculturais, tendo em vista a inserção historicamente problemática do Brasil no contexto identitário ibero-americano. ${ }^{5}$

Esta questão torna-se mais nítida quando observamos o menosprezo em relação a determinadas vertentes do siglo de oro espanhol (séculos XVI e XVII) detectável no tom utilizado pelos primeiros manuais de ensino de literatura do Colégio Pedro II, cujo alunado naquele momento era constituído, sobretudo, por membros da elite carioca e de outras regiões

\footnotetext{
${ }^{3} \mathrm{O}$ concurso para a cadeira de espanhol no Colégio Pedro II, ocupada primeiramente por Antenor Nascentes, ocorre após o aumento de subsídio para a criação da referida disciplina, aprovado pela Lei 3.674, de 7 de janeiro de 1919.

${ }^{4}$ Ressalte-se que, nos períodos mencionados, os aspectos relativos às literaturas hispânicas apareciam sempre nas cadeiras literárias do $7^{\circ}$ ano.

${ }^{5}$ No livro A América Latina existe?, Darcy Ribeiro discute essa problemática, remetendo-se, principalmente, às diferenças quanto às origens socioculturais e aos processos de colonização que se desenvolveram nas Américas portuguesa e espanhola. Segundo o intelectual, no conjunto denominado "América Latina" é possível "distinguir duas categorias contrastantes. Um conteúdo luso-americano concentrado todo no Brasil e um conteúdo hispanoamericano que congrega o restante. As diferenças entre uns e outros são pelo menos tão relevantes como as que distinguem Portugal da Espanha" (RIBEIRO, 2010, p. 25).
}

Rev. Bras. Lit. Comp. Niterói, v. 22, n. 41, pp. 117-131, set. /dez. 2020

https://doi.org/10.1590/2596-304X20202241aa 
do país. No livro Curso elementar de litteratura nacional, por exemplo, usado na instituição a partir de 1862, Joaquim Caetano Fernandes Pinheiro critica a ascendência do gongorismo sobre o lirismo português e justifica sua omissão a fim de afastar a juventude brasileira das influências desta estética considerada de "mau gosto":

A corrupção do gosto que já assignalamos na introducção a esta epocha, e a fatal influencia que a escola de Gongora exerceu sobre a poesia portugueza fez-se sentir de modo bem manifesto no genero lyrico e suas diversas especies. Nem-um dos poetas d'esse periodo póde ser apontado como modelo, e não desejando nós multiplicar citações inuteis, mas antes offerecer á juventude uma grinalda das mais odoriferas flores da litteratura nacional, omittimos essa pleiade de poetas gongorista, cujo brilhante europel poderia fascinar as suas verdes imaginações. (Pinheiro, 1862, p. 186)

Tal processo discursivo de depreciação que se estende a toda literatura barroca - cujos principais expoentes (Góngora, Quevedo, Calderón de la Barca etc.) pertencem ao cânone espanhol - é também discutido no célebre estudo $O$ seqüestro do barroco na formação da literatura brasileira: o caso Gregório de Mattos, de Haroldo de Campos. Nele, o autor nos mostra que esta depreciação continua a ocorrer, no âmbito da historiografia literária brasileira, mesmo na primeira metade do século XX, período em que houve uma forte revalorização em termos mundiais deste estilo literário:

[...] quando já ia em mais da metade o século mesmo da revalorização do Barroco (Dâmaso Alonso, Gerardo Diego, Garcia Lorca na Espanha; Eliot e os "metaphysical poets" em língua inglesa; Walter Benjamin e a reavaliação da "alegoria" como dispositivo estético no "auto fúnebre" da literatura alemã do período; Luciano Anceschi e a polêmica anti-Croce no quadro do "Ermetismo" italiano), coloca-se em dúvida, à vista dos "extremos do barroco literário", tanto a "autenticidade" quanto a "permanência da sua comunicação". (Campos, 1989, p. 34)

Este movimento de recusa do barroquismo, devido aos traços de hermetismo formal e obscuridade semântica, em prol das noções de clareza, harmonia e comunicabilidade atribuídas aos estilos neoclássico e romântico (associados, sobretudo, aos expoentes da literatura francesa), demostra que a história das ideias pedagógicas ${ }^{6}$ constitui um terreno de disputas atravessado por inúmeros discursos e pela mutabilidade e ressignificação de valores culturais, sendo a esfera do discurso literário uma das mais importantes neste complexo feixe de relações. ${ }^{7}$

No artigo "Presença da língua e da literatura francesa no Brasil (para uma história dos afetos culturais franco-brasileiros)", Silviano Santiago também nos oferece indícios da existência de uma assimetria no que tange às políticas linguístico-literárias, ao afirmar que, nos períodos do Império e da Primeira República, a classe letrada brasileira adotou o francês como língua "universal", de tal modo que na formação humanística e intelectual no Brasil foi sendo substituído paulatinamente o "estudo das culturas clássicas (em língua grega e, principalmente, em língua latina) pelo estudo do francês e de sua extraordinária literatura" (Santiago, 2009, p. 18). ${ }^{8}$ Isto ratifica ainda resultados trazidos à tona pela tese de doutorado de Dezerto (2013),

\footnotetext{
${ }^{6}$ Lançamos mão aqui da noção postulada por Moacir Gadotti no livro homônimo História das idéias pedagógicas (1993).

${ }^{7}$ Cabe, nesse sentido, fazermos uma crítica à retração do espaço oferecido aos conhecimentos literários na área de "Linguagens, códigos e suas tecnologias", desde o lançamento dos primeiros Parâmetros Curriculares Nacionais (PCN) em 1998, o que vem impactando o ensino básico e os estudos relacionados à formação de professores e à educação linguística.

${ }^{8}$ É importante mencionar que, no artigo supracitado, Silviano Santiago desenvolve parte de sua reflexão sobre a presença do francês e da literatura francesa no Brasil a partir de dados históricos do Colégio Pedro II.
} 
segundo a qual, ao longo do século XIX e primeira metade do século XX, a justificativa para o ensino de francês nos programas curriculares do Colégio Pedro II pautou-se, principalmente, sobre o aspecto civilizatório, como se a aprendizagem da língua francesa funcionasse como uma forma de suprir a ideia de "falta de cultura" - efeito imaginário legado à nossa memória discursiva pelo processo de colonização -, constituindo assim um instrumento de "acesso" aos dispositivos culturais de uma nação projetada enunciativamente como o "berço" da civilização ocidental.

\section{$* * * * *$}

É interessante notar, a partir deste ângulo comparativo, que as principais línguas estrangeiras modernas ensinadas no Brasil historicamente parecem possuir, portanto, distintas inserções na cultura letrada e no imaginário nacional, o que causa diferentes formas de posicionamento dos cânones literários vinculados a cada uma delas no contexto escolar. Se, por um lado, tais assimetrias glotopolíticas e educacionais estão ligadas à conjuntura histórica concernente às relações de poder e à hegemonia socioeconômica, elas estão também relacionadas, por outro, às formações discursivas ${ }^{10}$ que circunscrevem a construção das identidades nacionais. Isto implica dizer que a noção de dependência cultural não pode ser vista como um rótulo homogeneizador, dado que seria possível estabelecer, a exemplo do que temos visto, graus de hierarquização - pelo acionamento de diferentes estratégias discursivas - no que foi postulado como condição de dependência da literatura brasileira com relação às literaturas europeias.

Seguindo a esteira dessa colocação, talvez a performatividade discursiva dos manuais de ensino de literatura geral, usados nas escolas brasileiras desde meados do século XIX, tenha exercido papel crucial no processo de fragilização da associação entre língua e literatura espanhola no contexto escolar brasileiro. A nosso ver, isto traz à baila novos matizes para compreendermos as condições de possibilidade do discurso em que se ancora a proposição da cadeira de espanhol no Colégio Pedro II, no final da segunda década do século XX. No anúncio de sua criação, o ensino dessa língua aparece associado apenas ao de literatura hispanoamericana, num movimento de apagamento do campo da literatura espanhola, conforme se pode ver abaixo na nota publicada na imprensa carioca daquele período:

Havendo o governo da Republica Oriental do Uruguay creado uma cadeira de portuguez em um dos seus estabelecimentos officiaes, conforme a este ministerio communicou o das Relações Exteriores, declaro-vos para os devidos fins, que, nos termos do artigo 70, letra d, do decreto n. 11.530, de 18 de março de 1915, se devia crear nesse estabelecimento uma cadeira de frequencia facultativa, de lingua hespanhola, e litteratura hispanoamericana, como homenagem do Brazil ás demais nações que neste continente falam esse idioma, e como meio de facilitar e desenvolver o intercambio intellectual entre o nosso paiz e os povos hispano-americanos. (Jornal A Época, 31 de outubro de 1917, p. 5 - grifos nossos) $)^{11}$

De tais palavras, atribuídas a Carlos Maximiliano (ministro do Interior no governo Venceslau Brás), é possível depreender que o interesse do Estado brasileiro pelo ensino de

\footnotetext{
${ }^{9}$ Note-se que a noção de "cultura", de acordo com Eagleton (2005), está sendo entendida aí em sua acepção iluminista como equivalente a "civilização".

${ }^{10}$ Recorde-se que a noção de formação discursiva, desenvolvida por Michel Foucault, em A arqueologia do saber, remete a "um conjunto de regras anônimas, históricas, sempre determinadas no tempo e no espaço, que definiram, em uma época dada, e para uma determinada área social, econômica, geográfica ou linguística, as condições de exercício da função enunciativa" (Foucault, 2008, p. 144).

${ }^{11}$ Fonte consultada por meio da hemeroteca digital da Fundação Biblioteca Nacional.
} 
espanhol surge, durante a Primeira Guerra Mundial, em paralelo ao estreitamento de laços políticos com os países da América Hispânica. Por isso, sua implementação funciona como um gesto de reciprocidade em relação à adoção prévia do ensino de português no Uruguai ${ }^{12} \mathrm{e}$, por extensão metonímica, como forma mais ampla de "homenagem" aos "povos hispanoamericanos". Como podemos perceber, nas dobras desta discursividade estão subsumidos novamente determinados efeitos de evidência (cf. Pêcheux, 1988) cujo funcionamento no discurso, em primeiro lugar, ignora a diversidade cultural, linguística e literária das várias nações de língua espanhola espalhadas pelas Américas, uniformizando-as sob o rótulo de literatura hispano-americana. Além disso, simultaneamente, silencia-se aí qualquer tipo de estranhamento em relação à ausência da literatura espanhola no bojo dessa proposição caminho este, como dissemos antes, aberto pelo processo de minoração do peso epistemológico dos tópicos literários espanhóis no currículo escolar de literatura geral.

É interessante observarmos, a partir da trajetória oblíqua de desenvolvimento do campo disciplinar de língua espanhola e suas literaturas no contexto institucional do Colégio Pedro II, uma tentativa de esquivamento em relação à ideia de dependência cultural, o que pode ter servido de fator auxiliar no processo de desconstrução do princípio de influência, que parecia dominar o diálogo da literatura brasileira com as demais literaturas ensinadas na escola. Se entendermos o intento do governo brasileiro de estreitar laços com os países vizinhos como um dos primeiros passos do projeto político de integração regional latino-americana (cf. Arnoux, 1995), poderemos compreender, nesta acoplagem enunciativa da língua espanhola com a literatura hispano-americana, a realização de um dúplice agenciamento no âmbito das políticas linguísticas e das políticas literárias. Tal atitude, a nosso ver, logrou propiciar certa disrupção dentro da tendência a se estabelecerem diálogos verticalizados com o exterior que, sob a rubrica do cosmopolitismo, colocam as culturas europeias em patamar de superioridade.

Esta discussão assemelha-se à elaborada no conhecido ensaio "Literatura e cultura de 1900 a 1945", em que Antonio Candido analisa a dialética entre localismo e cosmopolitismo como eixo transversal da história literária brasileira. Nele, Candido considera as fases do romantismo e do modernismo como épocas de maior acirramento do conflito entre representações culturais cosmopolitas (vinculadas à noção de dependência do capital cultural europeu) versus representações culturais locais (relacionadas ao empenho intelectual e artístico de construção da identidade nacional). O estudioso também assinala que o período correspondente aos anos 1900 e 1922 - o mesmo em que se deu a criação da cadeira de espanhol no Pedro II - pode ser entendido enquanto etapa de arrefecimento do conflito entre o local e o cosmopolita. Esse momento histórico que antecede à geração de 22, segundo o crítico, é muito siderado pela noção de academismo, contra a qual os primeiros modernistas irão se rebelar mais fortemente do que contra a influência portuguesa na cultura brasileira, tal como fizeram os escritores românticos. Leiamos adiante um trecho do referido ensaio em que o autor define o que entende como academismo:

Comparada com a da fase seguinte (1922-1945), a literatura aparece aí essencialmente como literatura de permanência. Conserva e elabora os traços desenvolvidos depois do Romantismo, sem dar origem a desenvolvimentos novos; e, o que é mais interessante, parece acomodar-se com prazer nesta conservação. Como a fase 1880-1900 tinha sido, em contraposição ao Romantismo, antes de busca de equilíbrio que de ruptura, esta, que

\footnotetext{
${ }^{12}$ É importante chamar a atenção aqui para o fato de que as relações entre Brasil e Uruguai passaram por diversos conflitos bélicos e turbulências diplomáticas, ao longo do século XIX, tais como a Campanha da Cisplatina, a Guerra do Prata e a Guerra do Uruguai, as quais foram motivadas, dentre outros fatores, pelas investidas militares do Império do Brasil com vistas a obter a supremacia no território sul-americano. Cabe ainda fazer a ressalva de que Uruguai e Brasil, juntamente com a Argentina, formaram a chamada Tríplice Aliança durante a Guerra do Paraguai.
}

Rev. Bras. Lit. Comp. Niterói, v. 22, n. 41, pp. 117-131, set. /dez. 2020

https://doi.org/10.1590/2596-304X20202241aa 
a acompanha sem ter o seu vigor, dá quase impressão de estagnar-se. Uma literatura satisfeita, sem angústia formal, sem rebelião nem abismos. Sua única mágoa é não parecer de todo europeia; seu esforço mais tenaz é conseguir pela cópia o equilíbrio e a harmonia, ou seja, o academismo. (Candido, 2006, p. 119)

Tal reflexão suscita-nos o questionamento de determinadas tensões que atravessam o contexto histórico-educacional que estamos investigando. A primeira delas é que a ordem governamental para a criação da cadeira de língua espanhola, vinculada à literatura hispanoamericana, em 1917, emerge como uma espécie de "ponto fora da curva" em meio ao cenário pré-moderno, caracterizado, como pudemos constatar, pela adesão conservadora não só dos escritores, mas também dos catedráticos de literatura do ensino ginasial e secundário aos padrões estéticos eurocêntricos. Tal movimento vai ainda na contramão de certa hegemonia da presença da literatura espanhola, em contraposição à hispano-americana, nos currículos das disciplinas literárias do Pedro II. Ao analisar a legislação e os programas de literatura entre 1870 e 1942, Guimarães (op. cit., p. 71-72), por exemplo, aponta que, nos períodos de 1876 a 1880 e de 1925 a 1929, não se utilizava a expressão "literatura hispano-americana" para registrar a presença de tópicos literários hispânicos a serem lecionados na instituição.

Isto não significa que não houvesse pontos relativos à literatura produzida na América Hispânica em tais períodos, mas o que ocorria muitas vezes é que esta literatura era contemplada apenas de modo célere, como um "Rápido estudo da história literária dos povos hispanoamericanos" (ibidem, p. 77), dentro dos conteúdos de literatura espanhola incluídos nos programas de literatura geral. Mesmo nos anos posteriores à Semana de Arte Moderna de 1922, ocorrida em São Paulo, marco estabelecido por Candido para diferenciar o período de conservadorismo pré-moderno da fase de agitação modernista, é ainda possível perceber, na instituição de ensino carioca, outros indícios paradigmáticos de que a contradição aí é constitutiva ao discurso, de modo que as tentativas de ruptura com o status quo se veem imbricadas tensivamente à ordem da permanência e da estagnação estético-cultural. Um exemplo que queremos agregar aqui refere-se aos "Programmas de ensino do Collegio Pedro II", publicados no Diário Oficial, em 24 de março de 1929, nos quais a disciplina literatura, do sexto ano, apresenta também tópicos elencados sob o título de "Literatura espanhola" em que as manifestações literárias realizadas no contexto hispano-americano estão incluídas apenas no item final da sequência didática estabelecida, como se pode ver a seguir:

VII- Literatura espanhola

20 - Influencias dos Bascos, dos Arabes e dos Judeus - Literatura no periodo inicial: Auto de los Reyes Magos, Poema del Cid, Los Infantes de Lara - Affonso XI - El cantar de Rodrigo - Pero Lopez de Ayala - Epoca dos Reis Catholicos: Amadís de Gaula.

21 - O Seculo de Carlos V e de Felipe II - Influencias reciprocas da Italia, de Portugal e da Espanha; Gil Vicente; O Romance picaresco: Lazarillo de Tores [sic] - A Historia da Guerra de Granada de Diego Hurtado de Mendoza - O Mysticismo: Santa Thereza de Jesus.

22 - Cervantes; Lope de Vega - O Seculo de Felipe IV e de Carlos II; Gongora, Tirso de Molina, Calderon de la Barca.

23 - Literatura contemporanea — Sorilla [sic]; Campoamor; Castellar, Perez Escrich; Blasco Ibanez.

24 - Os autores da conquista: Correspondencia de Christovam Colombo, Hernan Cortez - Bartolomé de las Casas.

O regionalismo americano: como se deu a evolução da alma espanhola no Novo Mundo; o sopro da Independencia; a imitação romantica; modernas tendencias. 
Como foi possível observar até agora, o esforço de inclusão da literatura hispanoamericana, seja no campo disciplinar do ensino de história literária/literatura geral, seja no gesto de homenagem embutido na criação da cadeira de espanhol no Pedro II, configura-se nas primeiras décadas do século XX como um contraponto que se produz no interior mesmo de uma prática discursiva voltada para a "cópia" de determinados parâmetros canônicos europeus, vistos como injeção de cosmopolitismo necessária à elite letrada brasileira. Em outras palavras, a presença de conteúdo literário hispano-americano na estrutura curricular da mais importante instituição escolar da então capital federal, embora em posição também de "galho secundário" em relação à literatura da metrópole colonizadora (Espanha) e estereotipado sob a etiqueta "regionalismo americano", sinaliza uma vontade, ainda tímida e incipiente no decorrer da Primeira República, de se pensar a cultura brasileira em face do complexo cultural da América Latina, questionando, de algum modo, o histórico distanciamento do Brasil em relação às nações hispano-americanas. ${ }^{13}$ Tal atitude, entretanto, não chega a representar uma ampliação crítica da noção de "cor local" 14 em direção a uma identidade continental (transnacional) latinoamericana, tampouco rompe com o academismo beletrista, efeito sucedâneo do complexo de dependência cultural que constitui nossa memória discursiva.

Ao pensar o modo como esta distância se enraíza no imaginário brasileiro, emergindo até hoje em enunciados que circulam no senso comum" ${ }^{15}$, Maria Ligia Coelho Prado, no artigo "O Brasil e a distante América do Sul", assinala que a posição de isolamento brasileiro diante do concerto das nações latino-americanas se aprofunda durante o período do Império (1822-1889) devido à divergência entre o regime monárquico, adotado no Brasil e defendido pela sua classe dirigente, e o republicano, adotado pelas ex-colônias hispânicas logo após os movimentos de independência. A autora nos mostra também que tal distinção entre o Brasil e a América de colonização espanhola permaneceu durante a Primeira República Brasileira (1889-1930), pelo fato de não se ter produzido, naquele contexto, um discurso que opusesse, de modo contundente, ambos os períodos políticos no país. Segundo a historiadora:

A República [brasileira], devedora das ideias positivistas, foi entendida como uma etapa necessária ao maior progresso da nação. A monarquia precisava ser superada, mas isto não significava destruir o que ela havia legado à nação, a começar pela "manutenção da unidade e grandeza do território". A figura de D. Pedro II permanecia impoluta, aparecendo como um monarca bem intencionado e preocupado com os grandes problemas do Brasil. (Prado, 2001, p. 139)

É interessante refletir, neste sentido, que o Colégio Pedro II, fundado em 1837, possui, desde seu próprio nome, uma origem extremamente vinculada a este contexto sócio-histórico de valorização do regime monárquico no Brasil. Tal processo discursivo parece também refratar-se no modo como, por exemplo, a seção de literatura espanhola citada acima, parte do programa de literatura publicado em 1929, estabelece, em muitas passagens, correlação entre

\footnotetext{
${ }^{13}$ Emir Sader, no ensaio "Encontros e desencontros", discute, a partir de pressupostos das ciências sociais e políticas, esse apagamento da identidade latino-americana no imaginário brasileiro. O autor chega a afirmar que "Vista do Brasil, a América Latina não existe. [...] Em nossa identidade não se inclui ser um país 'latinoamericano'." (Sader, 2006, p. 177).

${ }^{14}$ No clássico ensaio "Notícia da atual literatura brasileira: instinto de nacionalidade", publicado originalmente em 1873, Machado de Assis discute o impacto da ideia de "cor local" na literatura brasileira do século XIX.

15 Esse lugar-comum, a nosso ver, vem criando inclusive condições de possibilidade para que emerjam discursivamente atos legislativos que interferem, autoritariamente, no planejamento linguístico e na organização curricular da educação básica, tal como a Lei $\mathrm{n}^{\circ}$ 13.415/2017, que impõe o inglês como única língua estrangeira obrigatória a ser ensinada nas escolas brasileiras, revogando, por sua vez, a Lei 11.161/2005, que obrigava a oferta (ainda que em caráter facultativo) da língua espanhola em todo o ensino médio.
} 
autores clássicos e diferentes fases da monarquia espanhola, evidenciadas pelas referências aos monarcas Alfonso XI, Reis Católicos, Felipe IV etc. Por outro lado, no mesmo rol de conteúdos programáticos, concede-se espaço, ainda que diminuto, para a abordagem de gerações literárias de ideário republicano que surgiram a partir do "sopro" das independências na América Hispânica. Ou seja, com base nisto, a hipótese que construímos é que subjaz dentro da aparente estagnação academista do Pedro II - que se prolonga para além do evento inaugural do modernismo brasileiro, conforme dissemos - uma possível disputa ideológica, agenciada provavelmente tanto pelos professores e intelectuais que ocupavam as cátedras quanto pelos discentes da instituição, fazendo com que a própria atividade de textualização do currículo produzisse elos sub-reptícios entre posicionamentos discursivos conflitantes (monarquista vs. republicano; anti-latino-americanista vs. pró-latino-americanista).

$* * * * *$

Como temos visto, a ambivalência de posições no terreno do político, no segundo quartel do século XX, desdobra-se, em nosso ponto de vista, na tensão, vislumbrada no campo literário, entre performances discursivas que ora ratificam a memória em torno da condição de dependência cultural do Brasil, ora contestam este lugar reivindicando formas menos verticalizadas de diálogo e comparação com o outro. Observemos, como exemplo, um fragmento da apresentação do livro Literaturas estrangeiras, de A. Velloso Rebello, utilizado para o ensino de literatura no Colégio Pedro II, já durante a Era Vargas:

Em cada brasileiro culto ha um sonhador de cousas europeas, cada espirito positivo volta-se para a América do Norte e são esses os nossos modelos, porque só a inspiração permanece bem nacional.

José de Alencar, o mais brasileiro dos romancistas, é apontado como imitador de Cooper.

Penso não errar affirmando que temos romancistas e chronistas parisienses, novellistas que pelo "humour" seriam comprehendidos pelos inglezes, scientistas allemães e até professores que nas suas cathedras professavam doutrinas "sovieticas".

Não será inutil a leitura deste livro, porque o que um esquece ou despreza, outro descobre. (Rebello, 1936, p. 7-8)

Ao analisarmos esse trecho, podemos identificar que as assertivas do enunciador giram em torno da noção (que permanece no nível do não-dito) de emulação, entendida enquanto imitação de padrões estilísticos, gêneros discursivos e, até mesmo, visões de mundo e ethos político-ideológicos atribuídos a contextos socioculturais específicos, como se fosse possível estabelecer lugares fixos para as ideias, desconsiderando o processo de dispersão e ressignificação das práticas discursivas em diferentes circuitos culturais. Deste modo, o manual de ensino de literaturas estrangeiras projeta-se como uma obra necessária (i.e., 'não-inútil') porque ajudaria os alunos/leitores a 'descobrirem' aquilo que teria sido apagado pelo processo de 'esquecimento' das influências que constituiriam nossa identidade e, consequentemente, nossa literatura. Não à toa, o enunciador opta logo no início do excerto pelo recurso da ironia ao dizer: "só a inspiração permanece bem nacional" -, desconstruindo, por um lado, a ideia de autenticidade, vinculada pelo movimento romântico ao sentimento de nacionalidade, e posicionando, por outro lado, o estudo de literaturas estrangeiras como instrumento formativo fundamental no âmbito de uma cultura letrada entendida como dependente, visto ser capaz de levar os discentes a um patamar ("culto") de compreensão dos "modelos" assimilados pela intelligentsia brasileira. Cabe-nos ainda ressaltar que tais modelos, apontados em um compêndio escolar de meados da década de 1930, durante o governo constitucional getulista, remetem não só à Europa, mas também aos Estados Unidos, nação a que se confere uma 
ascensão de natureza tanto econômica quanto artístico-literária. Isto demonstra que o cânone, noção a que a de dependência cultural paga tributo, não é uma categoria estática, e sim dinâmica e passível de modificações de acordo com os contextos histórico-ideológicos.

$\mathrm{Na}$ esteira dessa reflexão, é necessário observar também que, no rol das nacionalidades visibilizadas pelo enunciador, não consta qualquer referência à literatura de Espanha ou dos países hispanofalantes da América. No entanto, a tensão a que nos referimos acima se indicia, de maneira subliminar, no funcionamento desse discurso, criando efeitos a posteriori, visto que o livro de A. Velloso Rebello, assim como outros manuais de literatura geral (ou estrangeira) usados naquele período contêm capítulos sobre literatura espanhola, a qual, embora em grande parte recusada esteticamente pelos literatos brasileiros, pode ter servido de base para a formação intelectual de críticos que décadas depois empreenderam, por exemplo, o processo tardio de valoração estética do barroco no Brasil. ${ }^{16}$ Além disso, como ocorre em outras obras didáticas desta modalidade, o último capítulo do compêndio é dedicado à literatura hispano-americana, o que, como já discutimos, abre caminho para se pensarem distintas possibilidades de conexão da literatura brasileira com a multipolaridade do sistema literário latino-americano - temática esta que se torna mais recorrente em nosso meio acadêmico, por exemplo, após a publicação pela Unesco da coletânea América Latina en su literatura (1972), que reúne intelectuais de renome não só da América Hispânica, mas também do Brasil, dentre os quais estão inclusive os críticos cariocas Antonio Houaiss e José Guilherme Merquior.

Esse movimento de revisão crítica, seja da relação Brasil-América Latina, seja do lugar da produção latino-americana diante da dinâmica cultural global, ganha outro importante impulso, advindo da crítica literária realizada nos círculos universitários do Rio de Janeiro, com a publicação do ensaio "O entre-lugar do discurso latino-americano", de Silviano Santiago, publicado no livro Uma literatura nos trópicos, cuja primeira edição data de 1978. Neste texto, Silviano problematiza, de maneira frontal, o entendimento da ideia de dependência cultural como via de mão única e condição inelutável de inferiorização perante a presença de valores estéticos eurocêntricos no campo artístico-literário brasileiro. O ensaísta promove um diálogo singular entre a antropofagia oswaldiana e o pensamento borgiano, no intuito de - sem abandonar ingenuamente a questão da dependência em jogo nas relações de poder-saber travadas entre o primeiro e o terceiro mundo - propor uma mudança de perspectiva em relação aos processos de deslocamento e reescritura crítica da tradição produzidos a partir do diálogo com o legado cultural do Ocidente. Desta forma, o autor assinala que o método sistemático da crítica conservadora, voltado para a análise da influência europeia no Brasil, "apenas assinala a indigência de uma arte já pobre por causa das condições econômicas em que pode sobreviver", acentuando "por ricochete a beleza, o poder e a glória das obras criadas no meio da sociedade colonialista" (Santiago, 2000, p.17).

Evidentemente, desde meados do século XX, muitos movimentos de problematização da noção de dependência têm sido levados a cabo em várias áreas do conhecimento, tanto no cenário acadêmico internacional quanto no brasileiro. ${ }^{17} \mathrm{Em}$ paralelo a isso, a forte propaganda nacionalista empreendida pelo Estado Novo e pela Ditadura Militar no Brasil, junto a sucessivas reformas educacionais - tais como a Reforma Capanema de 1942, a Lei de Diretrizes e Bases (LDB) de 1961 e a LDB de 1971 - que foram reduzindo o caráter humanístico da educação secundária, transformando-a cada vez mais em uma espécie de preparatório para o ensino superior, aprofundaram o processo de diminuição do espaço das literaturas estrangeiras no

\footnotetext{
${ }^{16}$ Podemos citar como exemplo o conhecido estudo de Affonso Ávila, O lúdico e as projeções do mundo barroco (1971), um marco desse processo de valoração tardia do barroco no Brasil.

${ }^{17}$ Gostaríamos de assinalar, a título de exemplificação, com base em Muranyi (2012), o papel de mediador cultural exercido por Paulo Rónai - intelectual de origem húngara, naturalizado brasileiro, que foi professor catedrático de francês e latim do Colégio Pedro II nesse período -, cuja obra nos ajuda a questionar, por um lado, a ideia de dependência unilateral e, por outro, a de insularidade da literatura brasileira em relação às demais literaturas.
}

Rev. Bras. Lit. Comp. Niterói, v. 22, n. 41, pp. 117-131, set. /dez. 2020 
currículo escolar, que passou a enfatizar quase sempre apenas épocas e aspectos da literatura nacional. Outro ponto importante de se lembrar é que a retirada da obrigatoriedade do ensino de diferentes línguas estrangeiras, na LDB de 1961 e na LDB de 1971, enceta um processo de desoficialização do ensino de línguas na educação brasileira (cf. Rodrigues, 2012), criando lapsos na oferta destas disciplinas que podem ter impactado, decerto, a história de vinculação entre línguas e literaturas estrangeiras nas instituições educacionais.

É curioso notar, por outro viés, que, já na década de 1980, enquanto o campo disciplinar língua estrangeira moderna aderia à grande voga do comunicativismo, sobretudo, nos espaços não formais de ensino como os cursos livres e os clubes de línguas (cf. Leffa \& Irala, 2014), no circuito acadêmico - vinculado, principalmente, à formação em Letras Neolatinas - os saberes literários pareciam ser (ainda) os mais valorizados epistemologicamente. Tal paradoxo é assinalado, por exemplo, pela investigação de doutorado de Vargens (2012), que demonstra, por meio das programações de palestras apresentadas durante o I Seminário de Estudos Hispânicos (1982) e o II Seminário de Estudos Hispânicos (1983), realizados pela Associação de Professores de Espanhol do Estado do Rio de Janeiro (APEERJ), a presença de uma imensa maioria de trabalhos vinculados ao campo dos estudos literários em contraposição ao número de comunicações relacionadas aos estudos linguísticos e de ensino de línguas. Segundo a autora, a ausência de trabalhos deste tipo nos referidos eventos indica "que os saberes privilegiados por esses profissionais centravam-se na literatura" (ibidem, p. 98).

Ratificando, todavia, a presença de movimentos conflitantes e paradoxais, na emaranhada trama da memória concernente à interface entre saberes linguísticos, literários e pedagógicos no Brasil, em 1985 - período muito próximo ao abordado no parágrafo anterior - o Plano Geral de Ensino (PGE) do Colégio Pedro II apresenta, na contramão da hegemonia acadêmica do literário, um programa de língua espanhola cujo enfoque privilegia aspectos lexicais, gramaticais e exercícios de estímulo às habilidades linguísticas, como se pode verificar na seguinte citação:

1- Estudo do vocabulário e de compreensão de textos que levem, de maneira prática, à aquisição progressiva do léxico da língua e à assimilação de sua estrutura gramatical.

2- Aplicação do vocabulário e de estruturas gramaticais adquiridas em diálogos, em resumos, em redações, em versões e traduções.

3- Fixação dos fatos gramaticais da língua, por meio de exercícios orais e escritos.

4- Audição, sempre que possível, de discos e fitas em espanhol. (PGE, 1985 apud Bevilaqua, 2017, p. 72)

Seria possível enxergarmos, neste silenciamento da literatura no plano de ensino de espanhol do Pedro II destacado acima, certo "receio" em relação à abordagem do literário, provocado talvez pela existência de um hiato no âmbito da formação docente entre os campos de estudos linguísticos e literários? ${ }^{18}$ A resposta a esta pergunta é obviamente positiva se levarmos em conta o perceptível afastamento em relação às discussões estético-literárias na bibliografia acadêmica sobre ensino/aprendizagem de línguas estrangeiras na contemporaneidade. No entanto, em lugar de apenas apontarmos a falha gerada por essa ausência no campo dos estudos linguísticos, queremos nos interrogar aqui também em que medida esse receio e esse afastamento não poderiam derivar, simultaneamente, de certo "nó" em torno das polêmicas e dos debates relacionados à questão da dependência cultural no campo dos estudos literários. Ou seja, perguntamo-nos assim até que ponto a universidade hoje tem dado subsídios para que os professores da escola básica possam articular textos e aspectos

\footnotetext{
${ }^{18}$ Fugazza (2016) associa esse hiato a um processo de clivagem de identidades acadêmicas no contexto da formação inicial em Letras, em sua dissertação de mestrado intitulada Formações linguísticas e literárias na licenciatura em Letras Espanhol: discurso e concepções teórico-práticas.
} 
literários estrangeiros aos seus planejamentos pedagógicos, evidenciando frutíferos processos de reelaboração discursiva desencadeados pelo diálogo crítico com a alteridade, sem recair na armadilha do beletrismo eurocêntrico. ${ }^{19}$

Por meio dessas indagações, queremos dar visibilidade à problemática da dependência cultural como ponto espinhoso no bojo da memória que atravessa a formação das identidades docentes na área de línguas e literaturas estrangeiras modernas, conforme tratamos de analisar através desta história das ideias pedagógicas no Colégio Pedro II. No que tange especificamente à docência em língua espanhola, essa memória "difícil" torna-se ainda mais complexa, a nosso ver, pelos lugares incômodos e provocativos ocupados pelas literaturas espanhola e hispanoamericana dentro deste histórico. Isto talvez explique que mesmo nos dias atuais, quando debates a respeito da interculturalidade vêm se tentando fazer mais visíveis nas pesquisas sobre língua(gem), continue havendo um forte silenciamento da esfera literária em projetos políticopedagógicos e programas de ensino de línguas estrangeiras no ensino fundamental e médio.

Como vimos, diversos movimentos afetaram (e seguem afetando) a memória em torno do papel formativo do texto literário estrangeiro tanto no ensino/aprendizagem de línguas quanto no processo de letramento. Ao discutir o conceito de memória discursiva, Pêcheux (1999, p. 56) afirma que esta não pode ser entendida como um "reservatório" de sentidos homogêneos e transcendentais, mas como espaço de desdobramentos, disputas, polêmicas e contradiscursos. E é justamente no terreno de disputas em torno desta memória que gostaríamos de inserir a intervenção crítica que ora estamos propondo. A nosso ver, é possível e necessário, enquanto professores e formadores de professores de línguas e literaturas, reinventarmos esta memória e reelaborarmos nossos "receios". Assim, poderemos interpelar a contribuição do conhecimento literário, evitando a vigência no contemporâneo de um processo discursivo de recalcamento da questão da dependência cultural ${ }^{20}$, com vistas a trazê-la à tona e rediscuti-la criticamente (a partir de uma perspectiva desierarquizante) no contexto da educação básica, em meio ao panorama de acelerada digitalização e mediatização dos intercâmbios na sociedade global.

Para finalizarmos, é importante frisar que, ao repensarmos hoje os sentidos em torno da literaturas estrangeiras no ensino de línguas, partimos de um olhar não subordinado ao didático, mas que enxerga "as práticas de ensino como condições de produção de processos de identificação" (Payer \& Celada, 2016, p. 38), subvertendo assim a concepção utilitarista da presença do texto e do saber literários no campo disciplinar língua estrangeira moderna. Fazemos, portanto, uma defesa de que haja uma presença produtiva das literaturas estrangeiras, tanto na universidade quanto na escola, a fim de propiciar reflexões sobre a heterogeneidade constitutiva do discurso e as tensões que atravessam o sujeito e a cultura.

\section{REFERÊNCIAS}

ARNOUX, E. Las políticas lingüísticas en los procesos de integración regional. Signo y seña, Buenos Aires, n. 4, p. 11-27, 1995. Disponível em: http://revistascientificas.filo.uba.ar/index.php/sys/article/view/5439. Acesso em 01/03/2020.

ASSIS, M. de. Notícia da atual literatura brasileira: instinto de nacionalidade. In: Obra Completa. Vol. III. Rio de Janeiro: Aguilar, 1973, p. 801-809.

ÁVILA, A. O lúdico e as projeções do mundo barroco. São Paulo: Perspectiva, 1971.

\footnotetext{
${ }^{19}$ Daher (2011) explora criticamente os impactos da herança do beletrismo, vinculada à tradição bacharelesca dos cursos de Letras no Brasil, para a formação de professores.

${ }^{20}$ Remetemos os leitores a dois outros ensaios de Silviano Santiago, "Apesar de dependente, universal” (1982) e "O cosmopolitismo do pobre" (2002), em nossa opinião fundamentais para o aprofundamento do debate teóricocrítico a respeito da noção de dependência cultural.
}

Rev. Bras. Lit. Comp. Niterói, v. 22, n. 41, pp. 117-131, set. /dez. 2020 
BEVILAQUA, M. C. O ensino de espanhol no Colégio Pedro II (1985-1988): trajetórias entre saberes e práticas de ensino. In: SANTORO, M. et al. (org.) História do Colégio Pedro II. Rio de Janeiro: Colégio Pedro II, 2017, p. 67-78.

BRASIL. Decreto $n^{\circ} 4.468$, de $1^{\circ}$ de fevereiro de 1870 . Altera os regulamentos relativos ao Imperial Collegio de Pedro II.

de Pedro II.

Decreto $n^{\circ} 6130$, de $1^{\circ}$ de março de 1876 . Altera os Regulamentos do Imperial Collegio de Pedro II.

Decreto $n^{\circ} 6884$, de 20 de abril de 1878. Altera os Regulamentos do Imperial Collegio de Pedro II.

. Decreto $n^{\circ} 8.051$, de 24 de março de 1881. Altera os regulamentos do Imperial Collegio Nacional.

Decreto $n^{\circ} 1075$, de 22 de novembro de 1890. Approva o regulamento para o Gymnasio

Decreto $n^{\circ} 2857$, de 30 de março de 1898. Approva o regulamento para o Gymnasio Nacional e ensino secundario nos Estados.

II.

Decreto $n^{o} 8.660$, de 5 de abril de 1911. Approva o regulamento para o Collegio Pedro

. Decreto $n^{o} 11.530$, de 18 de março de 1915. Reorganiza o ensino secundario e o superior na Republica.

Lei $n^{\circ}$ 3.674, de 7 de janeiro de 1919. Fixa a Despeza Geral da Republica dos Estados Unidos do Brasil para exercicio de 1919.

Programmas de ensino do Collegio Pedro II para o anno de 1929. Diario Official Estados Unidos do Brasil. Rio de Janeiro: 24 de março de 1929.

Decreto-Lei $n^{\circ} 4.244$, de 9 de abril de 1942. Lei orgânica do ensino secundário.

Nacional.

Lei $n^{o}$ 4.024, de 20 de dezembro de 1961. Fixa as Diretrizes e Bases da Educação

. Lei $n^{\circ} 5.692$, de 11 de agosto de 1971. Fixa Diretrizes e Bases para o ensino de $1^{\circ}$ e $2^{\circ}$ graus, e dá outras providências.

Parâmetros curriculares nacionais: terceiro e quarto ciclos do ensino fundamental. Brasília: MEC/SEF, 1998.

. Lei $n^{\circ} 11.161$, de 5 de agosto de 2005. Dispõe sobre o ensino da língua espanhola.

Lei $n^{\circ} 13.415$, de 16 de fevereiro de 2017. Altera as Leis $\mathrm{n}^{\circ} 9.394$, de 20 de dezembro de 1996, que estabelece as diretrizes e bases da educação nacional, e 11.494, de 20 de junho 2007, que regulamenta o Fundo de Manutenção e Desenvolvimento da Educação Básica.

CAMPOS, H. Sequestro do barroco na formação da literatura brasileira: o caso Gregório de Mattos. Salvador: FCJA, 1989.

CANDIDO, A. Formação da literatura brasileira: momentos decisivos. Belo Horizonte: Ed. Itatiaia, 2000.

. Literatura e cultura de 1900 a 1945. In: Literatura e sociedade. Rio de Janeiro: Ouro sobre Azul, 2006, p. 117-146.

CELADA, M. T. O espanhol para o brasileiro: uma língua singularmente estrangeira. Campinas: Tese de doutorado - IEL/Unicamp, 2002.

DAHER, D. C. Formación de docentes de ELE: ¿Cualificación para el trabajo en las escuelas brasileñas? In: CASTELA, G.; FANJUL, A. (org.) Línguas, políticas e ensino na integração regional. Cascavel: ASSOESTE, 2011.

DEZERTO, F. Francês e Colégio Pedro II: um processo de construção de um campo disciplinar escolar (de 1838 a 1945). Niterói: Tese de doutorado - Programa de Pós-graduação em Estudos de Linguagem/UFF, 2013.

EAGLETON, T. A idéia de cultura. São Paulo: Ed. Unesp, 2005.

FOUCAULT, M. A arqueologia do saber. Rio de Janeiro: Forense Universitária, 2008. 
FUGAZZA, E. Formações linguísticas e literárias na licenciatura em Letras Espanhol: discurso e concepções teórico-práticas. Rio de Janeiro: Dissertação de Mestrado - Programa de Pós-graduação em Letras Neolatinas/UFRJ, 2016.

GADOTTI, M. História das idéias pedagógicas. São Paulo: Ática, 1993.

GUIMARÃES, A. Panaméricas utópicas: a institucionalização do ensino de Espanhol (18701961). São Cristóvão/SE: Dissertação de Mestrado - PPG Educação/UFS, 2014.

LEFFA, V. J.; IRALA, V. B. O ensino de outra(s) língua(s) na contemporaneidade: questões conceituais e metodológicas. In: LEFFA, V. J.; IRALA, V. B. (org.) Uma espiadinha na sala de aula: ensinando línguas adicionais no Brasil. Pelotas: Educat, 2014, p. 21-48.

MORENO, C. F. (coord.) América latina en su literatura. México D.F.: Siglo XXI/Unesco, 1972.

MURANYI, H. Archipelago or continental island? Reflections on Brazilian insularity. In: ETTE, O.; MÜLLER, G. (eds.) Worldwide: archipels de la mondialisation. Madrid/Frankfurt am Main: Iberoamericana/Vervuert, 2012, p. 309-316.

PAYER, M.; CELADA, M. (org.). Subjetivação e processos de identificação. Sujeitos e línguas em práticas discursivas - inflexões no ensino. Campinas: Pontes, 2016.

PÊCHEUX, M. Semântica e discurso: uma crítica à afirmação do óbvio. Campinas: Editora da UNICAMP, 1988.

. Papel da memória. In: Achard, P. et al. (org.) Papel da memória. Campinas: Pontes, 1999, p. 49-58.

PINHEIRO, J. C. F. Curso elementar de litteratura nacional. Rio de Janeiro: Livraria de B. L. Garnier, 1862.

Antonio Andrade é professor associado da Universidade Federal do Rio de Janeiro e pesquisador do CNPq. Mais informações em http://lattes.cnpq.br/9416610899767382

Submetido em 03/05/2020

Aprovado em 13/06/2020 